\title{
Sofrimento psíquico na equipe de transplante de medula óssea - uma revisão integrativa
}

\section{Emotional distress on the interdisciplinary health team of hematopoietic stem cells transplantation- an integrative review}

\author{
Daphne R. Pereira ${ }^{1}$, Elaine A. Cortez ${ }^{2}$
}

\begin{abstract}
RESUMO
Modelo: Revisão integrativa de publicações com modelo descritivo.

Objetivo do estudo: Identificar e analisar artigos referentes ao impacto da rotina do transplante sobre a saúde mental da equipe interdisciplinar de transplante de medula óssea.

Metodologia: Foram utilizadas as bases de dados LILACS, Embase, ProQuest e Medline, além do Portal da UNIFESP e da Editora Atheneu; com artigos pesquisados nos idiomas inglês, português e espanhol, sem limite de data de publicação e cujo foco era o profissional de saúde.

Resultados: Observou-se um hiato na produção científica em relação a este viés, pois a maioria dos trabalhos privilegia o desenvolvimento dos aspectos técnicos - tanto do procedimento, quanto da equipe que realiza o transplante -, em detrimento da atenção aos fatores psíquicos que permeiam a práxis do profissional de saúde.

Conclusões: Os achados, apesar de escassos, confirmam a hipótese inicial de que há um sofrimento psíquico na equipe de TCTH e sinalizam a lacuna existente de pesquisas na área. É proposta uma discussão, com diversos referenciais teóricos, para tentar compreender o que subjaz a esta questão.

Palavras-chave: Equipe de Assistência ao Paciente; Transplante de Medula Óssea; Estresse Psicológico.
\end{abstract}

\section{Introdução}

O transplante de medula óssea (TMO) ou, como recém renomeado, transplante de células-tronco hematopoéticas (TCTH), foi instituído na prática médica a partir do final da década de 60 , sendo empregado no tratamento de condições benignas crônicas e al- guns tipos de doenças malignas. O primeiro transplante de medula óssea foi realizado em 1956 por Edward Donnall Thomas (1920-2012), nos Estados Unidos e, até o final da década de 1960, quase 200 transplantes alogênicos de medula óssea foram realizados em seres humanos, sem sucesso a longo prazo. Entretanto, nesse período, os bons resultados dos transplantes uti-
1. Psicóloga do Centro de Transplante de Medula Óssea do Instituto Nacional de Câncer, Especialização em Terapia de Família;

2. Enfermeira, Professora Adju nta da Universidade Federal Fluminense Escola de Enfermagem Aurora de Afonso Costa, doutora e mestre pela Universidade Federal do Rio de Janeiro, especialista pela Universidade Estadual do Rio de Janeiro.
Correspondência: Psicóloga Daphne R. Pereira, Centro de Transplante de Medula Óssea do Instituto Nacional de Câncer (CEMO/INCA),

Praça Cruz Vermelha, 23, $7^{\circ}$ andar - Centro CEP 20230-130 - Rio de Janeiro - RJ e-mail: daphne.pereira@inca.gov.br

Artigo recebido em 17/07/2013 Aprovado para publicação em 24/01/2014 
lizando gêmeos idênticos como doadores trouxe alento para a continuidade das pesquisas nessa área. No Brasil, os estudos iniciais foram desenvolvidos por Ricardo Pasquini e sua equipe na Universidade Federal do Paraná (Curitiba), que realizou o primeiro transplante de medula óssea no país, em conjunto com o professor Eurípedes Ferreira, no ano de 1979. Essa iniciativa foi seguida, em 1982, pela equipe coordenada por Mary E. Flowers, no Instituto Nacional do Câncer, no Rio de Janeiro. ${ }^{1}$

O TCTH caracteriza-se por ser um procedimento de alta complexidade e especificidade, tendo como público-alvo pacientes que tiveram todas as outras tentativas terapêuticas fracassadas e que têm no transplante sua última tentativa, ainda que não haja neste garantia de que será bem-sucedido. Estes pacientes encontram-se bastante fragilizados, física e psiquicamente, após o insucesso dos tratamentos anteriores. Desta forma, o nível de investimento requerido da equipe de um centro de transplante é muito alto, tanto no que concerne à formação técnica, quanto à motivação e desejo de atuar numa enfermaria onde os pacientes vivenciam situações de intenso sofrimento.

Na mesma proporção - justamente por sua complexidade e incerteza - à medida que fracassa, o transplante mostra-se extremamente ansiogênico não somente para pacientes e familiares, como também para os profissionais que o realizam. Surpreendentemente, observa-se uma lacuna na produção científica em relação ao impacto dos estressores psicológicos deste tratamento sobre a equipe, já que a maioria dos artigos concentra-se no sofrimento psíquico dos pacientes.

A relevância deste estudo reside no fato que a atenção prestada aos diferentes vetores que interferem na práxis do profissional de saúde influencia, por conseguinte, a assistência prestada aos usuários e a prática hospitalar como um todo. Especificamente neste caso, trata-se de pessoas acometidas por doença grave, em muitos casos fatal, que as torna muito vulneráveis, requerendo maior cuidado daqueles que as acompanham.

Assim sendo, este estudo tem como questão: qual o impacto da rotina dos profissionais de saúde que atuam com o transplante sobre a saúde mental dos mesmos? Principalmente ao considerar-se a alta morbi mortalidade que o procedimento traz em contraposição ao alto investimento da equipe - cujo objetivo se refere, mormente, a "salvar vidas" e que se sente frustrada e impotente diante do sofrimento do paciente. E tem por objetivo identificar e analisar atra- vés de uma revisão integrativa artigos publicados sobre o sofrimento psíquico na equipe de TMO.

\section{Material e métodos}

Revisão integrativa, cujas buscas foram realizadas em março de 2013. Os critérios de inclusão foram: artigos publicados em português, inglês ou espanhol, sem limite de tempo da publicação, cujos sujeitos analisados fossem a equipe de saúde de centro de transplante de medula óssea. Critério de exclusão: trabalhos cujo foco exclusivo é o pacientes e/ou familiares, ainda que sejam estes os cuidadores. Foram pesquisadas as bases de dados: LILACS (portal CAPES), Medline (Portal PubMed), Embase, ProQuest e Editora Atheneu (Portal Saúde Baseada em Evidência/MS) e UNIFESP (Portal da UNIFESP).

Para melhor formulação de questão de pesquisa e de método de busca, foi utilizada a estratégia PICO (ou PIO), que representa um acrônimo para Paciente, Intervenção, Comparação e "Outcomes" (desfecho). Dentro do paradigma da Prática Baseada em Evidências (PBE), que prevê metodologias e processos para: a identificação de evidências de que um tratamento é efetivo; estratégias para avaliação da qualidade dos estudos e mecanismos para a implementação na assistência, esses quatro componentes são os elementos fundamentais da questão de pesquisa e da construção da pergunta para a busca bibliográfica de evidências. ${ }^{2}$ Neste estudo, "P" é Equipe Interdisciplinar; "I" Transplante de Medula Óssea e "O" Sofrimento Psíquico, conforme observado nas tabelas 1 e 2 e no fluxograma 1.

\section{Resultados}

No texto "Aspectos Psicológicos e Psiquiátricos do Transplante de Medula Óssea", os autores relatam a experiência do Serviço de Interconsulta e Psiquiatria na Unidade de Transplante de Medula Óssea dentro do Hospital das Clínicas da Faculdade de Medicina de Ribeirão Preto da Universidade de São Paulo (FMRPUSP). As conclusões encontradas derivam da atuação deste serviço, que conta ainda com a participação de psicólogos do Serviço de Psicologia Médica e dos outros membros da equipe multiprofissional junto ao paciente, seus familiares e grupos de apoio a profissionais. Este trabalho foi originalmente apresentado no Simpósio Transplante de Medula Óssea da instituição supracitada. ${ }^{3}$ 
Tabela 1: Bases Pesquisadas e Tesauros

\begin{tabular}{lllcc}
\hline Base de Dados & Portal & Tesauros & Resultados & Selecionados \\
\hline 1. Lilacs & & 1. Equipe de Assistência ao Paciente AND & 0 & 0 \\
& 2. Transplante de Medula Óssea AND \\
& 3. Estresse Psicológico & \\
CAPES & $-\ldots \ldots \ldots \ldots \ldots \ldots$
\end{tabular}

1. Equipe de Assistência ao Paciente AND

4

2. Transplante de Medula Óssea

2. Interdisciplinary Care Team AND

3. Bone Marrow Transplantation OR

4. Hematopoetic Stem Cells

Transplantation AND

Pubmed

5. Stress, psychological OR

6. Mental Health

7. death, Attitude

1. Patient Care Team OR

60

2. Interdisciplinary Care Team AND

3. Bone Marrow Transplantation OR

4. Hematopoetic Stem Cells

Transplantation AND

5. death, Attitude

3. Embase

1. Health care personnel AND

Portal da Saúde

2. Bone Marrow Transplantation AND

3. Mental Stress OR

0

0

4. Psychoanalysis

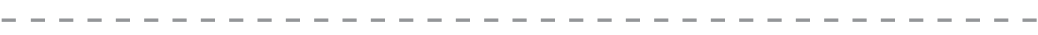

1. Health care personnel AND

2. Bone Marrow Transplantation AND

3. Mental Stress

1

0 
1. Health Care Personnel AND

2. Bone Marrow Transplantation AND

3. Mental Health OR Psychological Wellbeing

1. Health Care Personnel AND

2. Transplantation OR

3. Stem Cells Transplantation AND

4. Emotional Disorders OR Mental Health

1. Health Care Personnel AND

414

Busca

2. Stem Cells Transplantation AND

refinada

3. Emotional Disorders OR Mental Health

1. Health Care Personnel AND

2. Bone Marrow Transplant OR Hematopoietic Stem Cells Transplant AND

3. Emotional Distress OR Mental Health

0

0

\section{UNIFESP}

Portal de UNIFESP

1. Equipe de Assistência ao Paciente AND

0

0

2. Transplante de Medula Óssea

1. Transplante de Medula Óssea

0

0

- - - - - - - - - - - - - - - - - -

1. Equipe de Assistência ao Paciente

0

1. Cuidados Paliativos

0

0

0

6. Editora Atheneu

Portal da Saúde

1. Equipe de Assistência ao Paciente

0

0

1. Transplante de Medula Óssea $---$ 
Passo 1: Elaboração do "PIO", escolha das bases de dados: Lilacs, Medline e Embase e busca pelos tesauros.
Passo 2: Busca $=0$
Passo 4: Terceira busca na Embase, com novos tesauros, resultado $=311$.

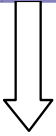

Passo 5: Adicionada a base de dados ProQuest, resultado $=1081$.
Passo 6: Nova busca na ProQuest, resultado $=414$.

Busca refinada na ProQuest, resultado final $=433$.
Passo 8: Leitura dos resumos e aplicação dos critérios de exclusão Lilacs (4), Medline (60), Embase (312) e ProQuest (433), totalizando 809. Apenas 2 textos (Lilacs e ProQuest) corresponderam aos critérios para análise.
Passo 3: Nova busca com outros tesauros (tabela 1): Lilacs $=4$, Medline $=60$ e Embase $=$ 1 (que foi logo descartado por ser fora da temática).

Fluxograma 1: Resumo da Metodologia de Pesquisa.

Tabela 2: Quadro Sinóptico dos Resultados

\begin{tabular}{|c|c|c|c|c|}
\hline Título & Autor & Ano & Periódico & Base \\
\hline $\begin{array}{l}\text { 1. Aspectos Psicológicos e Psi- } \\
\text { quiátricos do Transplante de } \\
\text { Medula Óssea }\end{array}$ & $\begin{array}{l}\text { José Onildo Betioli Contel; Alcion } \\
\text { Sponholz Jr.; Luciana M Torano- } \\
\text { Masetti; Ângela C Almeida; Érika } \\
\text { A Oliveira; Jorge Silvandro de } \\
\text { Jesus; Manoel Antônio dos } \\
\text { Santos; Sonia R Loureiro e Júlio } \\
\text { C Voltarelli. }\end{array}$ & 2000 & $\begin{array}{l}\text { Medicina (Ribeirão Preto) } \\
\text { Revista da Faculdade de } \\
\text { Medicina de Ribeirão Pre- } \\
\text { to e do Hospital das Clí- } \\
\text { nicas da FMRP Universi- } \\
\text { dade de São Paulo }\end{array}$ & LILACS \\
\hline $\begin{array}{l}\text { 2. Death, dying and emotional } \\
\text { labour: problematic dimen- } \\
\text { sions of the bone marrow } \\
\text { transplant nursing role? }\end{array}$ & $\begin{array}{l}\text { Daniel Kelly; Sharon Ross; } \\
\text { Benjamin Gray and Pam Smith. }\end{array}$ & 2000 & $\begin{array}{l}\text { Journal of Advanced } \\
\text { Nursing }\end{array}$ & ProQuest \\
\hline
\end{tabular}


No paper "Death, dying and emotional labour: problematic dimensions of the bone marrow transplant nursing role?" há uma dissertação acerca das equipes que trabalham em Centros de Transplante de Medula Óssea e as implicações do que os autores chamam de "trabalho emocional" (termo cunhado por Hochschild), principalmente no que tange à enfermagem, porém mencionando também o staff médico, no University College Hospital em Londres, Inglaterra. ${ }^{4}$

\section{Análise}

Apesar da escassez de publicações sobre o tema, é interessante observar que os dois textos ${ }^{(3,4)}$ convergem bastante em seus achados. Há pontos que são abordados por diferentes prismas, não chegando a ocorrer divergência entre eles. Os resultados demonstrados pelos autores são baseados em dados empíricos e relatos de caso, no primeiro texto e em revisão da literatura, no segundo.

Ambos os textos iniciam falando a respeito da complexidade do TCTH e das consequências deste sobre a saúde física e mental dos pacientes ${ }^{(3,4)}$; mesmo daqueles que, aparentemente, encontram-se em boas condições ao serem internados. Seguem analisando que tal fato contribui para que as pesquisas nesta área se restrinjam a aspectos técnicos (tecnológicos e biomédicos), negligenciando questões subjetivas concernentes à área, tais como: o estresse singular do paciente submetido a ele e as dificuldades da equipe em lidar com suas limitações no manejo das intercorrências. Acrescenta-se a isso a significativa mortalidade de pacientes - às vezes ainda na fase de condicionamento, quando não toleram a agressividade dos quimioterápicos -, assim como a frequiência com que ocorrem estas perdas e o sofrimento experimentado pela equipe pode ser sentido como intolerável e gerador de importante cisão nas relações interpessoais.

No trabalho apresentado pela equipe de Ribeirão Preto $^{3}$, é relatado o fechamento da Unidade de TMO três vezes desde o início de suas atividades em 1992, tanto por falta de pessoal qualificado, como por um "colapso mental da equipe" 3 ( $\mathrm{sic}$ ). Em outra passagem do texto, os autores falam sobre o elevado grau de estresse na equipe como potencialmente causador de uma fragmentação interna. No estudo britânico apresentado no paper $^{4}$, os autores destacam os achados obtidos pela literatura acerca do impacto das mortes subsequentes (causadas pela AIDS) na comunidade gay como desencadeador de sentimentos de an- siedade e raiva, traçando um paralelo com a exposição a perdas vivenciadas pelo staff, podendo levar a um sentido de inutilidade de seus papéis.

Ainda no segundo artigo ${ }^{4}$, os autores sinalizam que as pesquisas qualitativas realizadas têm como foco principal a mensuração de aspectos objetivos da Qualidade de Vida (QOL) dos pacientes pós-TCTH, privilegiando questões funcionais; viés também examinado em "Aspectos Psicológicos e Psiquiátricos..."3 que, ao realizar a análise integrada de dados, observa que os pacientes correlacionam qualidade de vida à atividade física e funcionalidade. Por um lado, tal ênfase contribuiu para que se repensasse a indicação (bioética) para aqueles cujas vidas ficariam extremamente comprometidas, de maneira que a equipe avalia como sendo este o momento de mudar o objetivo do tratamento de curativo para paliativo. Todavia, por outro lado, fracassou na captura de elementos mais subjetivos experimentados pelos pacientes e, consequentemente, pelos profissionais envolvidos neste contexto. $\mathrm{O}$ aspecto principal, pontuado por ambas as publicações ${ }^{3,4}$, reside na falta de garantia de um tratamento potencialmente desencadeador de grande sofrimento físico e mental. De forma que tal incerteza permeia todas as etapas do transplante, sendo extremamente ansiogênica para os pacientes e para a equipe.

Após analisar as questões levantadas, o caminho encontrado pelos profissionais de Ribeirão Preto ${ }^{3}$ para minimizar tal impacto, foi a instituição de um grupo de apoio para os funcionários que funciona há cerca de 20 anos e que trouxe como principais contribuições o aperfeiçoamento das atividades e ambiente de trabalho, permitindo a sobrevivência do mesmo. Já o artigo britânico aponta a necessidade de se realizarem mais pesquisas na área, foco de interesse dos autores do citado estudo.

\section{Discussão}

A principal questão trazida por esta análise é que o procedimento do TCTH produz um alto impacto não somente para quem se submete a ele (e seus familiares), como também para os profissionais que o realizam.

Os motivos que subjazem a estes efeitos, devido aos poucos dados produzidos, somente podem ser aventados. O primeiro aspecto é a própria formação acadêmica, em especial a médica, que procura excluir a subjetividade a qualquer preço. Como diz Jean Clavreul: 
Representante hodierno típico do discurso da ciência (...) o discurso médico prima por excluir a subjetividade tanto daquele que o enuncia como daquele que o escuta. Daí a pretensa objetividade do cientista que, na verdade, está calcada na abolição da subjetividade do autor (...) O médico só se autoriza por não ser ele próprio, por ser ele próprio o menos possível. ${ }^{5-11}$

O autor pontua que a evasão da subjetividade é o que causa sofrimento ao médico e, aqui, estendemos esta concepção para outras áreas da saúde que incorporam esta prática de dessubjetivação. Contrariamente ao que se pensa, é justamente por não compartilhar aquilo que experiencia, que o profissional fica impedido de superar seu próprio sofrimento diante de "não poder fazer mais nada" pelo paciente terminal". Seguindo nesta linha, encontramos em Pitta ${ }^{6}$ a constatação do desaparelhamento do homem atual para lidar com a morte. A autora compara a sociedade medieval com a contemporânea, onde ocorre a dissociação entre a vida - sua transitoriedade - a naturalidade do adoecer e o morrer. A consequiência disto é que se evita, ao máximo, falar da morte, na ilusão de que isto serviria para não precisar lidar com ela, mesmo dentro de uma enfermaria de pacientes graves. $\mathrm{O}$ staff assim procede por temor de que sentimentos e reações descontroladas irrompam, trazendo sensação de falta de controle, algo que é tido como extremamente ameaçador por todos. Freud ${ }^{7}$ também traz importante contribuição acerca da incapacidade do homem em enfrentar a morte. Fala sobre a não inscrição desta no inconsciente sendo, portanto, inaceitável no que tange a nossa própria finitude e daqueles que amamos, tal como o homem primevo. E, assim como lemos em Pitta ${ }^{6}$, sinaliza como, ao contrário do homem primitivo, nos afastamos da capacidade de lidarmos com a morte como algo inerente à vida, passando a olhá-la como algo contingencial, a ser evitado a todo custo. Por fim, propõe uma "regressão" àquele momento, como forma de se reaprender a encarar nossa efemeridade.

Os casos clínicos, muito frequentemente, não fornecem de início, uma lógica evidente. E é justamente o que se apresenta como questão no caso que articula a equipe em torno do trabalho da clínica. Assim, "A Equipe" não existe antes do levantamento da questão e do trabalho proposto por esta. Não existe simplesmente como um laço institucional, pois, pensa- da deste modo, a equipe nada mais é do que profissionais presos as suas rotinas. A verdadeira equipe só se constitui em torno da construção de um caso clínico, que exige como consequiência o trabalho de muitos. ${ }^{8,9}$ A partir daí, elaboramos a hipótese que tal dificuldade em abordar claramente o assunto da terminalidade induz à falsa compreensão da morte como um fracasso do tratamento e da equipe, se configurando como raiz de alguns problemas de comunicação dentre os próprios profissionais e deles com o paciente/família. A questão é abordada no artigo "Death, Dying and emotional labour..." , que menciona pesquisa realizada por Knight e Field, cuja conclusão é que, ao evitar informar sobre o risco de morte iminente, tenta se evitar também seu enfrentamento, pois se receia que a rotina de trabalho possa se despedaçar diante de tal constatação. Todavia, tal comportamento não faz com que as questões simplesmente desapareçam e o malestar gerado acaba por se manifestar de alguma forma. Como lemos em Jackson:

\section{Se as tentativas de comunicação continuarem a ser mal-sucedidas, tais fracassos talvez le- vem ao aumento do desconforto e da evitação de uma comunicação mais clara com pacientes e suas famílias, resultando na di- minuição do investimento na relação medi- co-paciente, no aumento da ênfase da im- portância da cura e diminuição da satisfação no trabalho, possivelmente conduzindo ao burnout. ${ }^{(10: 897)}$}

No contexto do transplante, a desaprovação das manifestações de conteúdo emocional tanto por parte daqueles que o realizam, quanto daquele que o vivencia, deixaria muitas histórias sem serem ouvidas. Aqui, encontramos respaldo na obra Reflexões sobre a Vida e a Morte ${ }^{11}$ sobre a abordagem psicológica para pacientes terminais. A autora diz que o sujeito sabe de sua morte quando esta se aproxima dele e que é preciso que o ajudemos para que ele diga o que sabe. Mas, como suportar ouvir a enunciação de sentimentos relacionados à finitude, se isso nos remeteria a algo insuportável para o homem atual: a sua própria morte?

\section{Conclusões}

O primeiro ponto a ser considerado é que, a despeito dos poucos dados disponíveis em relação ao cenário pesquisado, a questão se confirma como ob- 
jeto de pesquisa. Isto é: qual o impacto da rotina do transplante sobre a saúde mental da equipe interdisciplinar, especialmente no que tange à incerteza quanto ao seu sucesso e à frustração do profissional de saúde ao sentir-se impotente diante do sofrimento intenso do paciente e sua família?

Um viés a ser analisado refere-se à dificuldade da sociedade hodierna em lidar com o envelhecimento, o adoecer e a morte. Busca-se, a qualquer preço, prolongar a juventude e o que é "belo", afastando tudo o que não corresponda a este modelo. Desta forma, diferentemente do homem medieval, para quem a finitude estava presente de forma mais clara e direta, o homem atual parece acreditar que escamoteá-la sig- nifica vencê-la. E quando isso não é possível, uma sensação de ameaça irrompe, como se a isso correspondesse o caos.

Seguindo nesta diretriz e considerando o enorme hiato existente na literatura acerca deste aspecto do TCTH, que tem privilegiado o desenvolvimento do arsenal biomédico do mesmo, conjecturamos se é o estranhamento do homem quanto à sua própria morte que o torna tão inábil para abordar esta questão. Aparentemente, é justamente sua tentativa (fadada ao fracasso) de controlar a vida e a morte, negando esta última de todas as formas, que o deixa tão incapacitado para aprender com ela e então viver melhor com suas próprias limitações.

\begin{abstract}
S
Model: Integrative review of publications with descriptive model.

Study objective: This study aim to identify and analyze articles concerning the impact of routine transplantation on the mental health of the bone marrow transplantation interdisciplinary team.

Methodology: The databases used were LILACS, EMBASE, Medline, and ProQuest, besides Portal UNIFESP and Publisher Atheneu. Articles were searched in English, Portuguese and Spanish, without limit publication date, and whose focus was the health professional.

Results: It was observed there is a gap in the scientific literature regarding this bias, since most of the studies focuses on the development of the technical's aspects, both of the procedure, as of the team that performs the transplant, at the expense of attention to the psychological factors that underlie health professional's praxis.

Conclusions: These findings, although scarce, confirm the initial hypothesis that there is a psychological distress in HSCT's team and signal the gap in the researched area. It proposes a discussion with several theoretical frameworks, to try to understand what underlies this issue.
\end{abstract}

Keywords: Interdisciplinary Care Team; Bone Marrow Transplantation; Stress, Psychological.

\section{Referências Bibliográficas}

1. Tuoto EA. História da Medicina by Dr Elvio A Tuoto [homepage on internet]. O Primeiro Transplante de Medula Óssea. [Cited 2013 May 25]. Available from: http:// historyofmedicine.blogspot.com.br/2009/03/o-primeiro-transplante-de-medula-ossea.html.

2. Santos CMC, Pimenta CAM, Nobre MRC. A estratégia pico para a construção da pergunta de pesquisa e busca de evidências. Rev Latinoam Enferm. . 2007; 15: 508-11.

3. Contel JOB, Sponholz Júnior A, Torrano-Masetti LM, Almeida AC, Oliveira EA, Jesus JS, et al. Aspectos psicológicos e psiquiátricos do transplante de medula óssea. Medicina (Ribeirão Preto). 2000; 33: 294-311.

4. Kelly D, Ross S, Gray B, Smith P. Death, dying and emotional labour: problematic dimensions of the bone marrow transplant nursing role? J Adv Nurs. 2000; 32: 952-60.

5. Clavreul J. A ordem médica: poder e impotência do discurso médico. São Paulo: Brasiliense; 1978.
6. Pitta A. Hospital: dor e morte como ofício. 3. ed. São Paulo: Hucitec; 1999.

7. Freud, S. Reflexões para os tempos de guerra e morte. In: Obras completas de Sigmund Freud. Rio de Janeiro: Imago; 1996. (Edição Standard Brasileira, v.14). p. 327-39.

8. Lima MC. A construção do caso clínico na equipe interdisciplinar [article on internet]. [cited 2013 May 20]. Available from: http://www.hc.ufmg.br/gids/construcao_clinico.pdf.

9. Della Nina M. A Equipe de Trabalho Interdisciplinar no Âmbito Hospitalar. In: Oliveira MFP, Ismael SMC, organizadores. Rumos da Psicologia Hospitalar em Cardiologia. Campinas (SP): Papirus; 1995.

10. Jackson VA, Mack J, Matsuyama R, Lakoma MD, Sullivan AM, Arnold RM et al. A qualitative study of oncologist's approaches to end-of-life care. J Palliat Med. 2008; 11: 893906.

11. Rezende VL, organizador. Reflexões sobre a vida e a morte: abordagem interdisciplinar do paciente terminal. Campinas (SP): Unicamp; 2000. 